\title{
CONCEPÇÃO E DESIGN PARA MATERIAL DIDÁTICO ON-LINE: ESTUDO SEMIÓTICO E CONCEPÇÃO DE LINGUAGEM VISUAL DIGITAL PARA ELABORAÇÃO DE LAYOUT PARA E-LEARNING
}

\author{
SÃO PAULO/SP JUNHO/2018 \\ João Paulo Tenório da Silva - Belas Artes - jpclipe@yahoo.com.br \\ Tipo: Relato de Experiência Inovadora (EI) \\ Categoria: Métodos e Tecnologias \\ Setor Educacional: EDUCAÇÃO SUPERIOR
}

\begin{abstract}
RESUMO
O presente trabalho tem como objetivo mostrar a importância do Design na EaD (Educação a Distância) e as etapas para a concepção visual para o Material didático on-line, ajudando na potencialização do aprendizado do aluno. Nos últimos anos a Educação a Distância em instituições de ensino, órgãos governamentais e empresariais distribuídos pelo Brasil têm aumentado de maneira considerável, consequentemente fazendo crescer a contratação de profissionais para atuarem na área, como Designers Instrucionais, Revisores de textos, Editores de vídeos e Designers Multimídia ou Web Designers. Neste trabalho, destaca-se a importância do papel deste último, já que é no desenvolvimento do design onde conseguimos ter, cognitivamente, um entendimento da proposta pedagógica dos cursos específicos de EaD. No entanto, o ritmo de produção de cursos de e-Learning tem se assemelhado ao de uma linha de produção, sem a preocupação estética em estruturar cada curso com base nos paradigmas conceituais e referenciais de seu público-alvo. Este trabalho apresenta maneiras de relacionar o curso por meio da personificação visual semiótica, a partir de roteiros ou storyboard aplicados à sua navegação e o uso de elementos, como signos, cores e imagens, na elaboração da identidade visual.
\end{abstract}

Palavras-chave: EaD - Educação a Distância, Design, Concepção, Semiótica, Painel Semântico. 


\section{Considerações iniciais}

O termo "design" vem do inglês, tendo como base o latim designare, junção entre de e signum (marca, sinal), significando desenvolver, conceber. Já a expressão "design" surgiu no século XVIII, na Inglaterra, como tradução do termo italiano disegno, mas somente com o progresso da produção industrial e com a criação das Schools of Design é que esta expressão passou a caracterizar uma atividade específica no processo de desenvolvimento de produtos. (BOMFIM, 1995)

O design aplicado à EaD começa muito antes da chegada da tecnologia moderna e da era dos computadores, por isso é importante compreender quais foram os principais fatos na história do design que contribuíram para o desenvolvimento de layouts para um curso de EaD. Começamos com a arte na pré-história, onde encontramos desenhos em cavernas que contam as narrativas de como viviam os povos há milhares de anos. Por meio desses registros nas paredes, com expressões, cores e traços estilizados, é que fazemos o reconhecimento de uma história e que cabe ainda hoje dentro de um contexto que conseguimos compreender. Isso porque as formas e símbolos são derivados de elementos que reconhecemos, ou seja, possuem caráter semiótico.

A história do design também percorre as ilustrações de livros, pois estão diretamente relacionadas ao desenvolvimento das tecnologias de reprodução. Porém, muito antes da chegada dos primeiros processos de impressão, eram as tradições orais de contar de histórias que comunicavam estas narrativas, de geração em geração. Dentro da evolução da comunicação, a escrita que registrava as informações passou do registro em paredes para outras superfícies, como pedra, argila, madeiras e evoluindo do papiro da era egípcia para a utilização do pergaminho, até o aparecimento do papel. Na idade medieval, nos scriptorium dos monastérios, foram realizadas as primeiras ilustrações em livros, as quais permitiam uma melhor compreensão e contextualização dos conteúdos. Destaca-se o desenvolvimento das iluminuras, arte que alia a ilustração à ornamentação e que era muito utilizada em antigos manuscritos, ocupando normalmente tanto as margens como barras laterais, na forma de molduras, letras capitulares que iniciavam um parágrafo com formas ornamentais e com maior destaque. O artista William Morris, considerado eminência na história do design e associado ao movimento artístico britânico Arts \& Crafts, foi um dos principais responsáveis pelo desenvolvimento das artes têxteis e métodos tradicionais de produção. 
Figura 1 - William Morris. Hammersmith, Kelmscott Press, 1894.
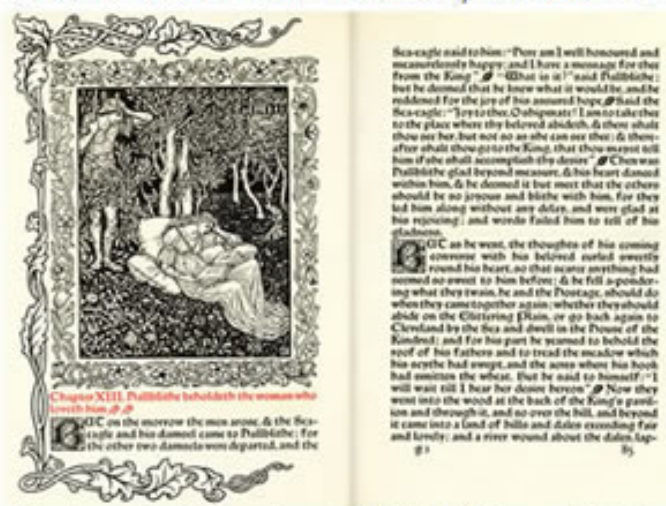

Fonte: pt.wikipedia.org/wiki/William_Morris.

Para o artista Leonardo Da Vinci, figura mais importante do alto do Renascimento, o desenho ultrapassava o papel para a realização de suas invenções, nasceu quase no mesmo ano da invenção, pelo alemão Johannes Gutemberg, da prensa de tipos móveis em 1450, máquina que acelerou o ritmo lento e trabalhoso da reprodução do texto escrito, logo passou pela xilogravura, evoluindo para a gravura em metal, cromolitografia, até as tecnologias de impressão digitais.

Foi graças ao avanço da tecnologia digital que foi possível o ensino a distância evoluir. A prática pedagógica em universidades, empresas, órgãos governamentais e treinamentos, que antes eram em locais físicos (off-line), tornou-se virtual (on-line). A $\mathrm{EaD}$, ou o e-Learning, é utilizado para o ensino realizado através de meios eletrônicos, por meio da Internet ou de intranet, utilizando diversos recursos como textos, imagens, vídeos, links, áudio, óculos de realidade virtual, entre outros. O alicerce visual dos cursos de EaD partiu da existência dos sistemas operacionais usados nos computadores da época de seu surgimento em meios digitais e nos recursos que eles ofereciam. Na década de 90, sua navegação e visual se tornou mais assertivo e acessível ao usuário graças à paradigmática influência do ambiente virtual do Windows 95, cuja interface resultava muito mais familiar que seus predecessores.

O grande desafio hoje é oferecer uma atmosfera visual que faça o aluno estabelecer uma imersão na disciplina. Atualmente compreendemos que o perfil de um aluno de EaD vem de um universo da tecnologia, possui experiência com aparelhos eletrônicos (computadores, smartphones e tablets) e tem conhecimentos básicos de informática, ou seja, está familiarizado com algum sistema operacional, seja ele Windows, iOS ou Android. Não obstante, faz-se necessária a disponibilização de guias, manuais e vídeos tutoriais que expliquem a utilização da ferramenta. Cada vez mais o cliente-aluno demonstra essa experiência e assume o direito de exigir um material moderno e que não seja repetitivo. Por isso, cabe ao Designer Multimídia ou Web Designer estar à frente nas tendências do ambiente visual digital para aplicação do design no material didático on-line, com a composição visual, diagramação, símbolos semióticos, pedagógicos e a experiência do usuário UX (User Experience), além de possuir o conhecimento sobre a 
história da arte e do design.

Os gestores da Educação a Distância nas instituições de ensino e órgãos governamentais e privados vêm assumindo uma grande responsabilidade ao tornar 0 material didático on-line mais eficaz, dinâmico e interativo, pois as ofertas de cursos aumentaram consideravelmente devido a quantidade de cursos autorizados e reconhecidos pelo MEC. Em outubro de 2015, a EaD do Centro Universitário Belas Artes de São Paulo em parceria com a Alice Ferraz, CEO da $F^{\star}$ hits lançaram o curso livre "Como criar um blog de moda - Fashion Blogging". O curso, com visual totalmente personalizado, gerou o artigo "A profissionalização dos blogues de moda por meio de design instrucional fechado" e foi destaque em várias mídias, como o site Estadão por Balmant. Em 2017, junto com a ABED (Associação Brasileira de Educação a Distância) - centro universitário lançou o "Prêmio ABED Belas Artes Design para EaD", incentivando a importância do design em projetos de EaD. Isso prova que esta é uma área muito importante e que merece reconhecimento e valorização. Um profissional formado e com experiência consegue atuar melhor na concepção do design para o material didático on-line.

Cada curso específico requer um tratamento diferenciado, pois são caminhos particulares, tanto pedagógica quanto visualmente, com os elementos e a diagramação da tela devendo ser diferentes uns dos outros. Isso demanda muita dedicação dos Designers Multimídia e Web Designers. Um dos principais fatores que o designer precisa saber antes de iniciar o desenvolvimento do design é conhecer os recursos da plataforma onde o curso ficará hospedado e familiarizar-se com suas limitações tecnológicas. O template (modelo, um "layout" ou "vestimenta" de um site), por exemplo, é um caso de destaque. Não adianta ter um layout em um template perfeito sendo que ele não é responsivo, ou seja, se adapta a todos os tamanhos de dispositivos móveis, no qual ele está sendo visualizado, redimensiona as imagens automaticamente para que caibam na tela e o template do site pode ser visualizado tanto em um dispositivo verticalmente como horizontalmente.

\section{Metodologia}

Foram utilizados os métodos de pesquisa indutivo, observação indireta, pesquisa qualitativa, dados empíricos, método descritivo e demonstração de técnicas de concepção através de painéis semânticos e palavras-chaves.

\section{Processo de produção}

Apontamos agora como funciona o processo de produção do material didático on-line. $\mathrm{O}$ problema dos LMS (Learning Management System) é que não focam no design, 
usabilidade e ergonomia. Um meio de prevenir essa carência do LMS, no requisito default (parâmetro padrão) é o uso das linguagens mais recentes para web, como 0 HTML 5 (Hypertext Markup Language) com o qual são desenvolvidos os websites, permitindo até o desenvolvimento do próprio material didático on-line.

Esses recursos da plataforma, somados à elaboração do layout do curso, são peças fundamentais no template. Tal e como indica Santaella (2001), os elementos sensoriais, tais como cores, formas, dimensão, luminosidade, composição e design, são responsáveis pela primeira impressão que o produto provoca no receptor. Nesse contexto, a autora ainda confirma que o cotidiano das pessoas está permeado de imagens, objetos materiais, signos que representam nosso meio ambiente visual. A importância da imagem também se destaca com Dondis (2003), em seu estudo da linguagem visual, o qual trata desde elementos prismáticos da luz branca e questões de pigmentação. $\mathrm{O}$ uso das cores no AVA é de grande importância, principalmente em mensagens de avisos ou botões que sinalizem o percurso das telas, evidenciando uma ação correta ou incorreta. Por fim, cabe remarcar a abordagem que aplica a perspectiva do aluno à importância sensorial e psicológica na visualização das cores, em Lupton (2015).

Após a contratação da plataforma LMS, o segundo passo é a produção das disciplinas EaD. O professor contratado pela instituição de ensino envia o seu plano de ensino para a coordenação da EaD, verificando a aderência na quantidade de horas e quantidade de módulos e seções do conteúdo do curso. A equipe EaD adapta o conteúdo enviado pelo professor a uma linguagem didática e dialógica, passando pelos Revisores ou Preparadores de Textos, pelos Designers Instrucionais, os quais montam os roteiros e storyboards de como se estruturará o conteúdo, e pelos Designers Multimídia ou Web Designers, que por sua vez desenvolvem a linguagem visual e as interações.

Figura 2 - Destaque no fluxo de trabalho do EaD, onde o Designer deve iniciar o trabalho.

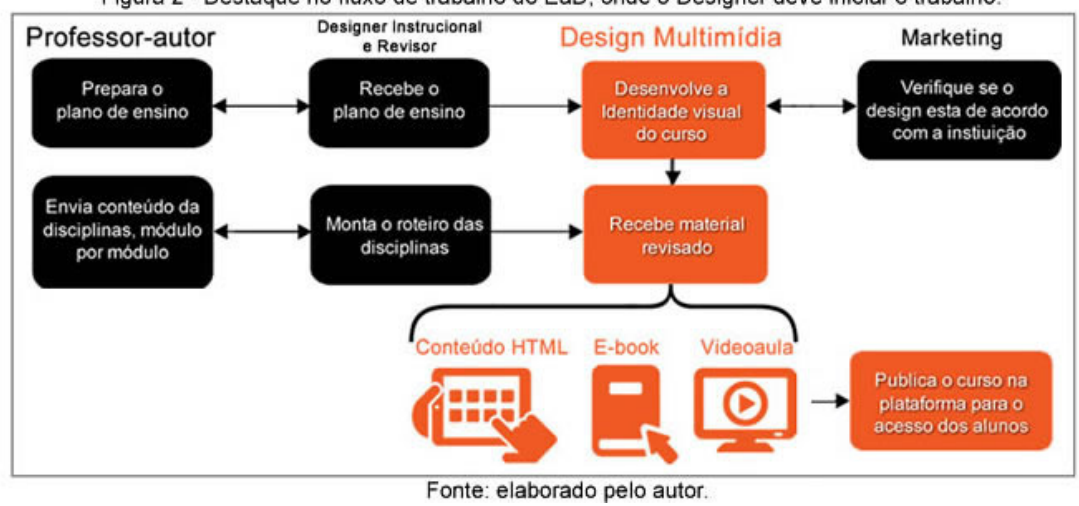

Para que exista um fluxo sistêmico, um processo eficiente na linha de produção dos materiais didáticos on-line, é importante não atrasar nenhuma das etapas. Neste primeiro passo é desenvolvido a identidade visual do curso, o qual é composto por logotipo e arte das capas dos módulos e seções. Já no segundo passo, recebemos o 
roteiro pelos Designers Instrucionais, ao qual é aplicado o design através de elementos multimídia e objetos pedagógicos.

\subsection{Concepção}

O processo mais rápido de conceber uma ideia é através de um rough (ou rafe no modo "abrasileirado"), que é o esboço de uma ideia executada de maneira rápida, sem muitos detalhes, mas suficiente para demonstrar os conceitos desejados. A mão é mais rápida que o mouse, portanto fazer um rough é mais rápido do que desenhar no computador ou em programas de layout e ilustração. Antes de iniciar a identidade visual do curso, é importante entender o processo estratégico do design, saber a quem será ofertado o curso, estabelecer o público-alvo, é importante entender o perfil do aluno. Por exemplo, um aluno de Administração será diferente de outro que esteja cursando Biologia.

Nesta primeira etapa, o mais importante é encontrar o "conceito" que representa o curso, com o uso de um Brainstorming, é onde encontra o conceito ou frase que determina o significado, percepção cognoscitiva, que caracteriza uma ideia, contemplando a essência e representação mental e linguística de um objeto concreto ou abstrato. Transforma-se a linguagem escrita em visual, ou seja, a busca por imagens que identifiquem ou traduzam a palavra ou o termo definido.

Após agrupar as palavras por categorias e buscar imagens que as representem, juntando-as em um painel semântico, pode-se ter uma visão panorâmica de diversas ideias. Medeiros (2006), ao contextualizar o estudo de design, semântica e emoção, relata que uma das primeiras inserções ao estudo da percepção semântica foi elaborada por Gibson (1986), com o conceito de affordances, para determinar que se percebe 0 meio ambiente e as coisas como significados, independente de repertório, interferências ou interpretações. Esta fase é resultante das fases anteriores, ou seja, de conclusões, amostras e informações que levam à concepção do modelo que pode ser entendido como uma representação que sintetiza as ideias em relação a um objetivo (MUNARI, 2000). No painel semântico inicial usamos as palavras-chave geradas pelo Brainstorming, como rastreio de grupos que caracterizam as palavras de conceito, buscando seu significado nos aspectos perceptivos e resultados como a cor e a tipografia.

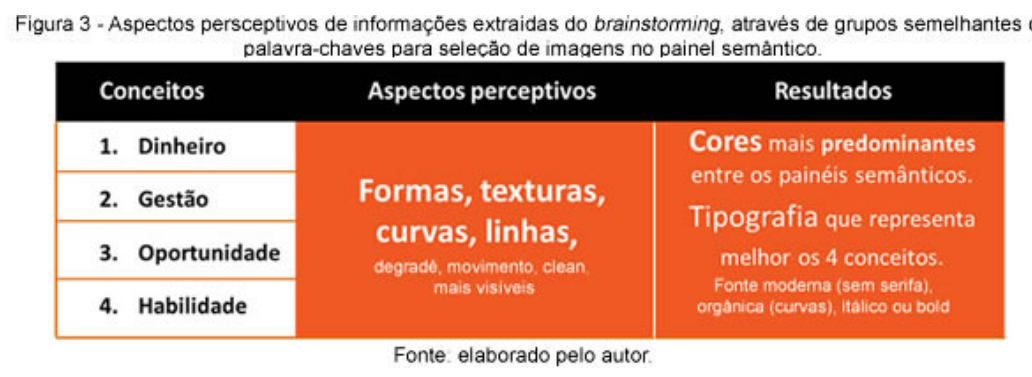


O painel semântico é uma ferramenta visual que conduz a inspiração por meio de imagens e é utilizado na decodificação de imagens. Constituído por imagens, a concepção desses painéis pode se dar por diferentes técnicas, que por sua vez recebem nomes como Mood Charts ou Mood Board, métodos de colagem de imagens que reúnem fotografias, imagens de revistas ou internet, desenhos, objetos, texturas e cores (GARNER \& MCDONAGH, 2008).

Segundo Baxter, "os produtos devem ser projetados para transmitir certos sentimentos e emoções [...] Isso pode ser conseguido construindo-se diversos painéis de imagens visuais" (BAXTER, 2000). No processo de construção dos painéis visuais, materialidades diversas são coladas, justapostas, superpostas ou fundidas, representando a dinâmica do pensamento. Os diferentes significados semânticos de termos ou conceitos podem ser muito diferentes entre os designers, técnicos e dirigentes de marketing (em uma equipe de desenvolvimento). Nos contextos nacional e global, isso se torna ainda mais complexo e pode gerar equívocos de entendimento (BAXTER, 2006). Para evitar um resultado negativo ao final do processo na construção da linguagem visual, a interação com o cliente é muito importante para localizar ajustes e mudanças, com a intenção de alinhar tais informações com o repertório do cliente. No caso, o cliente do setor da EaD é o professor-autor da disciplina. Ante esta informação, deve-se definir a mensagem visual que promova a comunicação com o seu público-alvo o (aluno).

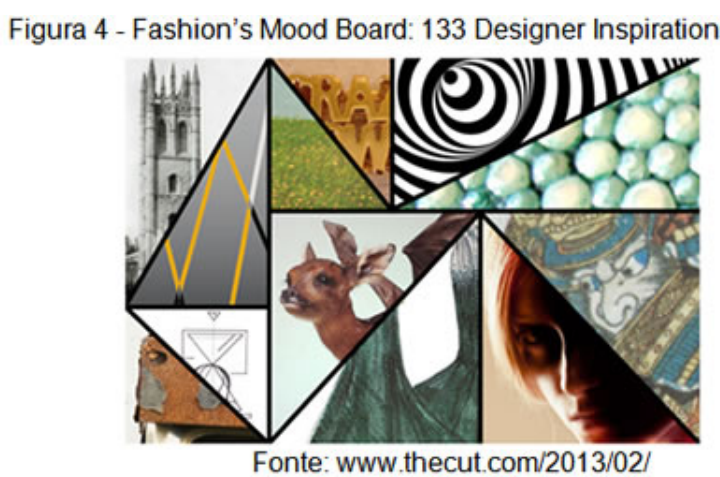

Os painéis de inspiração são definidos como "meios de comunicação visual ou multissensorial (textura, movimento, som) que podem ser úteis na construção do processo de comunicação e design" (MCDONAGH \& DENTON, 2005). Durante o processo de aprendizagem, são utilizadas ferramentas visuais que conduzem a confecção de painéis semânticos. As técnicas de concepção auxiliam na sistematização do processo, tornando-se parte do pensamento do design, para realizar a síntese imagética da comunicação, na observação do painel semântico são localizadas as cores mais predominantes para o desenvolvimento da paleta de cores. As formas são reconhecidas como linhas orgânicas ou retas, aliadas ao visual, que também ajudam na obtenção de imagens que podem ser relacionadas no processo de concepção. 
A primeira peça de design desenvolvida pelos Designers é o logotipo, pois podem ser definidos como elemento-base de uma identidade corporativa ou identidade de marca. Ainda, podem ser definidos como representação visual do que uma empresa, local ou produto são (BIRICIK, 2006). Um logotipo é composto pelo símbolo e pela tipografia, que juntos formam o logotipo em si. No desenvolvimento de um logotipo é muito importante a compatibilidade em sua legibilidade na internet, pois se trata de diferentes tamanhos de tela, onde serão acessados desde smartphones até smart TVs. Para evitar esse tipo de problema, Beaird (2012) afirma que fontes sem serifa possuem aparência contemporânea e proporcionam maior legibilidade em textos na web. É importante lembrar que, em alguns cursos de EaD, a vida útil é ignorada, tornando um produto desatualizado e que perde o interesse do usuário, além de gerar muitas críticas por parte de quem adquiriu o curso. Nestes casos é importante verificar se ainda existe compatibilidade com o perfil do seu público-alvo e atualização do conteúdo.

\subsection{Aplicação}

Os Designers recebem dos Dls o roteiro ou storyboard muito parecido com layout de um site. Dentre as principais bases utilizadas para o armamento deste layout que são os frameworks (ou biblioteca), optamos pelo Bootstrap, onde contém os principais arquivos em HTML, CSS (Cascading Style Sheets), e JS (JavaScript) para a produção das páginas, além de ser flexível e possuir um grid de 12 colunas, considerado ideal para o desenvolvimento de um projeto responsivo e focado em dispositivos móveis na web. Concordando com Lupton (2015), uma fonte comunica por meio de seus traços, de suas proporções e de seu peso visual. Os caracteres são agrupados em colunas e grids, em corpos de texto e títulos, além de em blocos e listas. Conforme Dondis (2003), os elementos visuais que compõem o layout de navegação do curso para o aprendizado são projetados inicialmente por linhas, traços e pontos. O termo signo, segundo a Teoria dos Signos desenvolvida por Charles S. Peirce, sob a perspectiva da crítica de processos de criação é definido como "qualquer coisa que, de um lado, é determinado por um objeto e, de outro, determina um efeito na mente de uma pessoa, denominado Interpretante do signo, que é, desse modo, mediatamente determinada por aquele objeto, em uma série infinita" (SALLES, 2011).

Para desenvolver um template inovador que possua as características do seu públicoalvo é necessário antes fazer um briefing analítico do perfil do aluno e uma análise de mercado que busque por tendências utilizadas na web. De acordo com um estudo realizado pela Universidade da Califórnia, em Los Angeles, que durou três anos e contou com a observação de mais de 800 adolescentes, foi constatado que mais de 5 mil horas da vida on-line são dedicadas a espaços como MySpace, Facebook, YouTube, Twitter e comunidades de games. Após o diagnóstico dos sites do perfil selecionado, é 
possível montar um layout moderno onde o aluno se identifique com o ambiente virtual. Desta maneira, o Designer consegue ser um excelente anfitrião aos usuários, mas é importante frisar que nem todas as tendências da web podem ser aplicadas à EaD. Conseguir chegar a um resultado de sucesso parte das primeiras etapas de concepção do design, das técnicas somadas à compatibilidade do sistema e às tendências da web devidamente implementadas. Um adequado seguimento desta pauta propiciará ao aluno uma melhor experiência com o curso de EaD e no seu aprendizado. Abaixo, o resultado da aplicação da identidade visual do curso e as tendências da web.

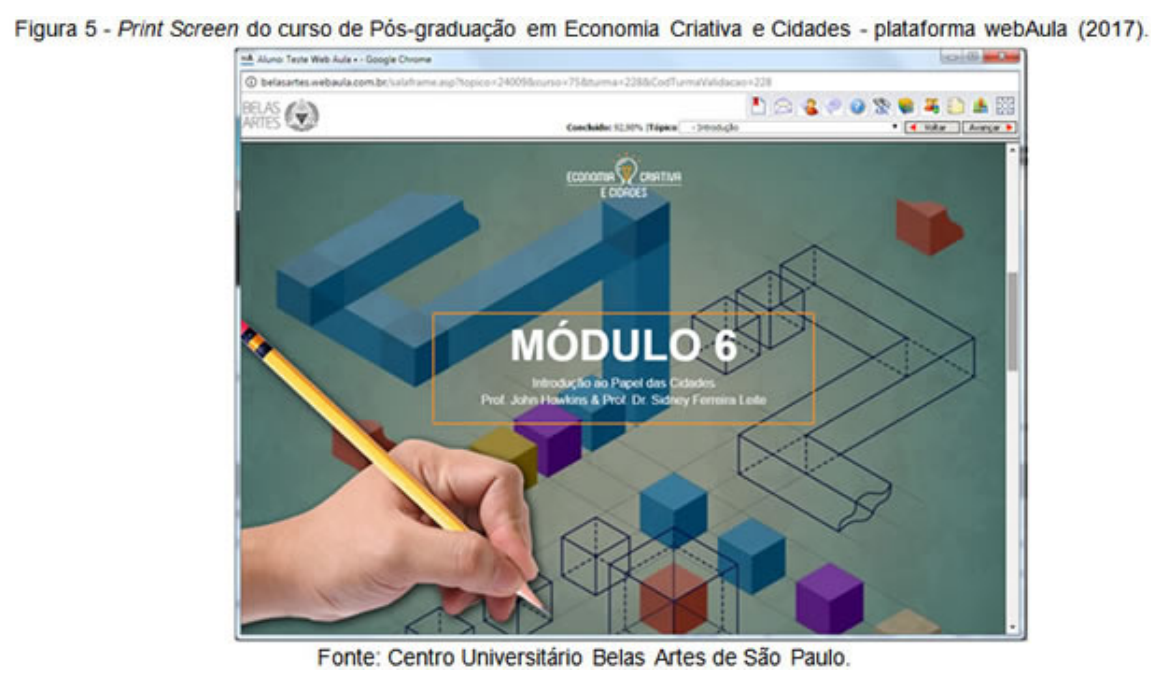

\section{Considerações Finais}

O resultado final deste trabalho para a renderização de layouts personalizados mais eficazes, só foi possível graças às etapas do processo de concepção para a produção do material didático on-line. No incentivo da abordagem de fundamentos primários para a concepção do design em e-learning, percorrendo a linguagem visual e semiótica. $\mathrm{O}$ processo de customização dos cursos EaD mostra que estamos caminhando para a nova geração da Web 3.0 que prevê que os conteúdos on-line estarão organizados de forma semântica, personalizados para cada internauta, com sites e aplicações inteligentes e publicidade baseada nas pesquisas e nos comportamentos de cada usuário.

\section{Referências}

BALMANT, Ocimara. Conectado, para aprender Comunicação a distância. Disponível em: ‘https://educacao.estadao.com.br/noticias/geral,conectado-para-aprendercomunicacao-a-distancia,10000072761. Acesso em: 20 de abril de 2017.

BAXTER, M. . Projeto de Produto: guia prático para o design de novos (2 ed.). São Paulo,: Edgard Blücher Ltda, 2003. 
BEAIRD, J. Princípios do Web Design Maravilhoso. Rio de Janeiro: Alta Books,, 2012. BIRICIK, A. The role of logo design in creating brand emotion: A semiotic comparison of the apple and ibm logos. Dissertação de Mestrado em Mestre de Ciências em Design Industrial da School of Engineering and Sciences of Izmir Institute of Technology, 2006. Disponível em:

〈http://citeseerx.ist.psu.edu/viewdoc/download?doi=10.1.1.427.5285rep=rep1type=pdf . Acesso em: 17 de abril de 2017.

BOMFIM, Gustavo Amarante. Metodologia para Desenvolvimento de Projetos. João Pessoa: Editora Universitária/UFPB, 1995.

DONDIS, Donis A. Sintaxe da linguagem visual. São Paulo: Martins Fontes, 2003. FARIAS, M. J. O. Dinâmicas Comunicacionais no Processo Criativo de Design de Produto:Característica e Construção da Linguagem a Partir dos Painéis Semânticos. São Paulo: Blucher, 2014.

GARDNER, Steve; MCDONAGH-PHILP, Deana. "Problem Interpretation and Resolution via Visual Stimuli: The Use of Mood Boards in Design Education". In: The Journal of Art and Design Education, 20 (1) pg. 57-64, 2001.

GIBSON, James J. The Ecological Approach to Visual Perception. Hillsdale: Lawrence Erlbaum Associates, 1986. Disponível em:

<http://books.google.com.br/books?id=DrhCCWmJpWUC

$\& p g=P A 127 \& d q=$ theory+of+affordances\&ei=AP88Ss3ql4- 6ygT4z8C6BQ . Acesso em: 20 de abril de 2017.

LUPTON, Ellen. Tipos na tela. São Paulo: Editora Gustavo Gili, 2015.

MCDONAGH, D., \& DENTON, H. "Exploring the degree to which individual students share a common perception of specific mood boards: Observations relating to teaching, learning and team-based design". Design Studies, 26(1), 35-53, 2005.

MEDEIROS, Wellington G. de. Interação Significante (IS): Dimensão Semântica da Interação de Usuários com Produtos. In: Anais do Congresso Brasileiro de Pesquisa e Desenvolvimento em Design (P\&D Design). , 7., 2006, Curitiba. Curitiba: AEND, 2006. 1 CDROM.

MUNARI, B. Das coisas nascem coisas. São Paulo: Martins Fontes, 2000.

SALLES, Cecilia Almeida. Gesto Inacabado: processo de criação artística. 5. ed. São Paulo: Intermeios, 2011.

SANTAELLA, Lúcia; NÖTH, Winfried. Imagem: cognição, semiótica, mídia. São Paulo: lluminuras, 2001.

O que é semiótica. São Paulo: Brasiliense, 1983. 